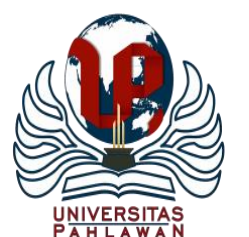

Jurnal Abdidas Volume 2 Nomor 5 Tahun 2021 Halaman 1110 - 1114

JURNAL ABDIDAS

http://abdidas.org/index.php/abdidas

\title{
Sosialisasi Penerapan Reduksi Sampah Organik Dari Larva Black Soldier Fly (FLY)
}

\author{
Febri Yanti ${ }^{\bowtie}$ \\ Pendidikan Kimia, Universitas HKBP Nommensen Pematangsiantar, Indonesia \\ E-mail : febriy192@gmail.com
}

\begin{abstract}
Abstrak
Sampah menjadi permasalahan besar seiring dengan pertambahan jumlah penduduk. Perlu manajemen pengelolaan sampah yang baik dimulai dari tempat pembuangan sampah sementara (TPS) hingga tempat pembuangan akhir (TPA). Teknologi biokonversi bahan organik bisa menjadi salah satu solusi permasalahan sampah larva lalat Black Soldier Fly (BSF) dapat dimanfaatkan untuk mengkonversi sampah organik. Sampah organik yang dapat didegradasi seperti sampah yang berasal dari sampah makanan (produk hewan maupun tumbuhan), sayur-sayuran, buah-buahan, limbah ikan, limbah pertanian dan perkebunan, limbah kayu, daundaunan, ranting serta kotoran hewan dan manusia. Kemampuan mendegradasi sampah larva BSF dilaporkan lebih baik dibandingkan serangga lainnya. Keberadaan Larva BSF dinilai cukup aman bagi kesehatan manusia, karena lalat ini termasuk binatang vektor penyakit. Tujuan dari kegiatan ini adalah meningkatkan pengetahuan dan ketrampilan peserta pelatihan menyelesaikan masalah lingkungan hidup yang berhubungan dengan mereduksi sampah organik dengan cara teknologi biokonversi sampah organik rumah tangga menggunakan larva lalat BSF. Pelaksanaan ini dilakukan dalam 2 sesi yaitu sesi pemaparan materi oleh pemateri dan sesi praktek reduksi sampah organik dengan meletakkan larva Black Soldier Fly (BSF) dengan pendampingan oleh pemateri. Pengabdian ini merupakan pengabdian kualitatif Hasil yang diperoleh $1 \mathrm{~kg}$ larva BSF di masukkan kedalam sampah organik larva tersebut mampu mereduksi sampah sekitar 2-3 kg sampah/hari.
\end{abstract}

Kata kunci: sosialisasi, sampah organik, larva black soldier fly (BSF)

\begin{abstract}
Garbage is a big problem along with the increase in population. Good waste management is needed starting from temporary waste disposal sites (TPS) to final disposal sites (TPA). Bioconversion technology of organic matter can be one solution to the problem of waste. Black Soldier Fly (BSF) larvae can be used to convert organic waste. Degradable organic waste, such as waste from food waste (animal and plant products), vegetables, fruits, fish waste, agricultural and plantation waste, wood waste, leaves, twigs and animal and human waste. BSF larval litter was reported to be better than other insects. The presence of BSF larvae is considered quite safe for human health, because these flies are disease vectors. The purpose of this activity is to increase the knowledge and skills of the trainees to solve environmental problems related to reducing organic waste by using household organic waste bioconversion technology using BSF fly larvae. This implementation was carried out in 2 sessions, namely a material presentation session by the speaker and a practical session on reducing organic waste by placing Black Soldier Fly (BSF) larvae with assistance by the speaker. This service is a qualitative service. The results obtained are $1 \mathrm{~kg}$ of BSF larvae are put into organic waste, the larvae are able to reduce waste by about 2-3 $\mathrm{kg}$ of waste / day .
\end{abstract}

Keywords: socialization, organic waste, larva black soldier fly (BSF)

Copyright (c) 2021 Febri Yanti

$\triangle$ Corresponding author

Address : Universitas HKBP Nommensen Pematangsiantar

Email : febriy192@gmail.com

DOI $\quad:$ https://doi.org/10.31004/abdidas.v2i5.434

ISSN 2721- 9224 (Media Cetak)

ISSN 2721- 9216 (Media Online) 


\section{PENDAHULUAN}

Sampah merupakan permasalahan besar seiring dengan pertambahan jumlah penduduk. Perlu manajemen pengelolaan sampah yang baik dimulai dari tempat pembuangan sampah sementara (TPS) hingga tempat pembuangan akhir (TPA). Keberlanjutan sistem pengelolaan sampah dapat dipertahankan dengan pembentukan program keterlibatan masyarakat untuk melakukan reduksi sampah. Pengelolaan sampah perlu teknologi yang tepat agar dapat mengatasi sampah dengan produk pengolahannya tidak menghasilkan sampah kembali. Teknologi biokonversi bahan organik bisa menjadi salah satu solusi permasalahan sampah (Ambarningrum et al., 2019). Larva lalat Black Soldier Fly (BSF) dapat dimanfaatkan untuk mengkonversi materi organik sehingga memiliki potensi ekonomi, dan mampu mendegradasi sampah organik. Sampah Organik yang dapat didegradasi seperti sampah yang berasal dari sampah makanan (produk hewan maupun tumbuhan), sayur-sayuran, buah-buahan, limbah ikan, limbah pertanian dan perkebunan, limbah kayu, daun-daunan, ranting serta kotoran hewan dan manusia (Mudeng et al., 2018). Sampah Organik tersebut tidak ditangani dengan baik dapat menjadi sumber penyebab penyakit, sumber pencemaran yang menghasilkan limbah cairan lindi yang dapat mencemari air, tanah dan gas metana yang mencemari udara serta dapat menimbulkan bau busuk (Rini Fahmi et al., 2009). Kemampuan mendegradasi sampah larva BSF dilaporkan lebih baik dibandingkan serangga lainnya (Azir et al., 2017). Keberadaan Larva BSF dinilai cukup aman bagi kesehatan manusia, karena lalat ini termasuk binatang vektor penyakit.

Pengabdian yang dilakukan sebelumnya oleh (Salman et al., 2020) menghasilkan produk dari pengolahan sampah organik oleh larva BSF dapat berupa : (a) telur larva BSF, (b) larva BSF (maggot), (c) kasgot (bekas maggot) merupakan residu dari biokonversi sampah organik oleh larva BSF dapat digunakan untuk media tanam budidaya sayuran, dan (d) lindi atau cairan yang didapat dari media pembesaran maggot, dapat digunakan sebagai pupuk cair. Pengadian yang dilakukan peneliti yaitu mensosialisasikan penerapan reduksi sampah organik dari larva Black Soldier Fly (BSF) kepada masyarakat di kelurahan Pardamean Kota Pematangsiantar.

Kegiatan ini dilakukan di Kelurahan Pardamean Kota Pematangsiantar. Lokasi ini merupakan daerah yang memiliki sampah rumah tangga yang banyak. Ada beberapa instansi pemerintah telah mengadakan sosialisasi di daerah ini untuk mendaur ulang sampah bahan anorganik menjadi alat kerajinan seperti limbah plastik, kertas dan lain-lain. Limbah organik tidak dikelola kembali hanya dibiarkan saja hingga membusuk, sehingga sering aroma yang tidak sedap didaerah tersebut akibat sampah organik. Untuk itu dilakukan sosialisasi untuk mengurangi sampah organik di daerah tersebut.

Tujuan dari kegiatan ini adalah meningkatkan pengetahuan dan ketrampilan peserta pelatihan menyelesaikan masalah lingkungan hidup yang berhubungan dengan mereduksi sampah organik dengan cara teknologi 
biokonversi sampah organik rumah tangga menggunakan larva lalat BSF.

\section{METODE}

Metode pengabdian yang dilakukan ini merupakan metode deskriptif. Kegiatan pengolahan limbah organik berupa limbah rumah tangga dengan melibatkan 15 orang dari masyarakat kelurahan Pardamean Kota Pematangsiantar. Kegiatan dilakukan selama 2 hari dan dimulai dari tanggal 14-15 Januari 2021. Pelaksanaan ini dilakukan dalam 2 sesi yaitu sesi pemaparan materi oleh pemateri dan sesi praktek reduksi sampah organik dengan meletakkan larva Black Soldier Fly (BSF) dengan pendampingan oleh pemateri. Tahapan kegiatan adalah sebagai berikut: (1). Pemaparan Materi di kantor lurah Pardamean. Materi yang di berikan adalah penerapan reduksi sampah organik dari larva Black Soldier Fly (BSF). Kegiatan pemaparan materi hanya dilakukan selama 1 hari di mulai tgl 14 Januari 2020, setelah pemaparan materi selesai 15 orang tersebut mengumpulkan sampah organik dari limbah rumah tangga dan di diamkan hingga membusuk. Kegiatan selanjutnya di tgl 15 Januari 2020 sesi kedua yaitu (2). Mempraktekkan reduksi limbah/sampah rumah tangga dengan meletakkan larva Black Soldier Fly (BSF). Cara Kerja di sesi kedua, sampah organik yang telah dikumpul dan dicacah menjadi ukuran yang lebih kecil yang telah membusuk dalam tong sampah, lalu dimasukan larva BSF yang telah di peroleh dari penelitian sebelumnya oleh peneliti. Kemudian di biarkan sampai larva memakan sampah organik yang membusuk dengan rakus. Peserta sosialisasi mengamati hal terjadi dan mencatat berapa lama larva BSF menghabiskan atau memakan sampah organik tersebut dengan perbandingan sampah yang dikumpulkan dan banyak larva BSF yang diletakkan.

\section{HASIL DAN PEMBAHASAN}

Sesi pertama yaitu pemaparan materi, masyarakat sangat antusias menerima materi yang disampaikan. Saat pembelajaran berlangsung, terjadi interaksi yang baik antara peserta dan pemateri. Kegiatan ini berlangsung selama 2-3 jam.

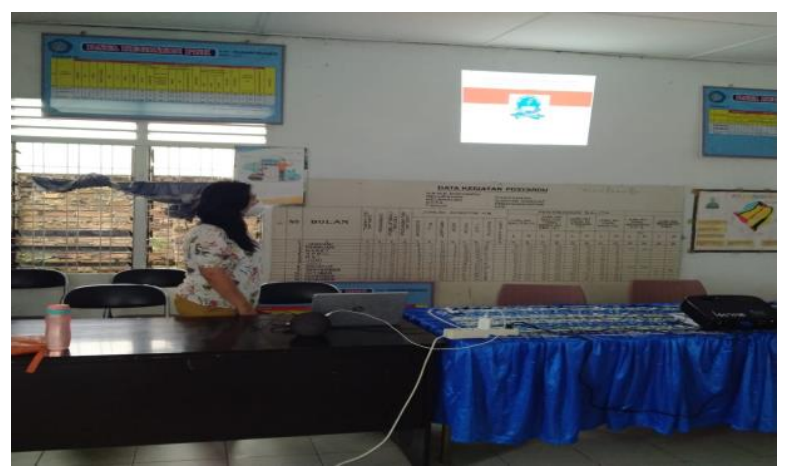

Gambar 1. Memberikan Materi

Pada akhirnya tujuan pemaparan ini tercapai sangat baik yaitu, menambah pengetahuan peserta tentang pengolahan limbah organik dan semangat peserta dalam mengikuti kegitan sosialisasi ini.

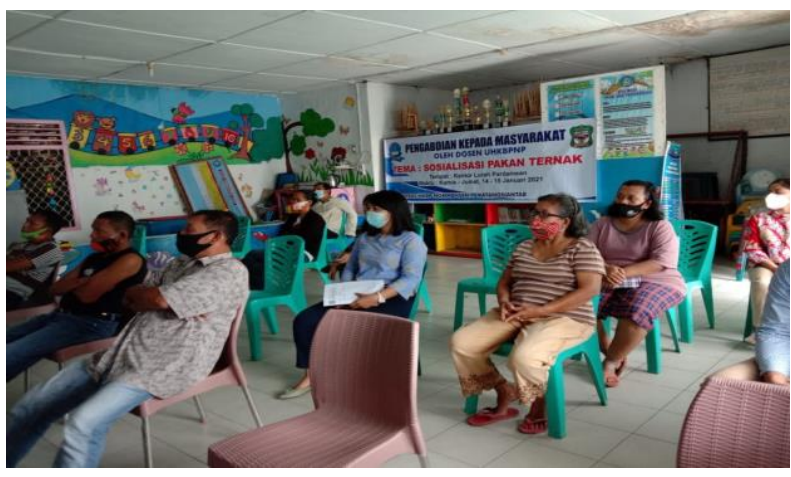

Gambar 2. Peserta Sosialisasi 
Setelah menerima teori yang telah dipaparkan pada sesi pertama, peserta diajak untuk mempraktekkan ilmu yang didapat untuk mengolah sampah organik melalui larva BSF.

Sebelum mempraktekkan peserta di suruh mengumpulkan sampah organik rumah tangga didalam 1 tempat sampah yang besar. Selanjutnya sampah dibiarkan begitu saja.

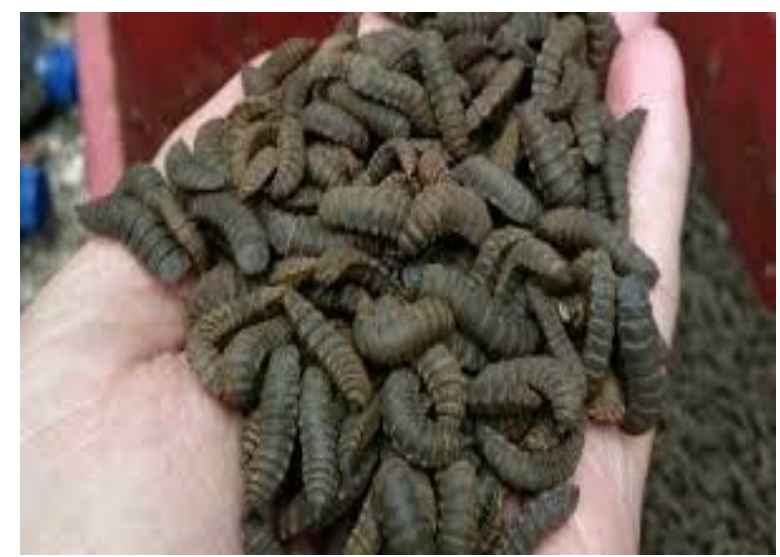

Gambar 3. Larva Black Soldier Fly (BSF)

Pada hari berikutnya tgl 15 Januari 2021 di kelurahan pardamean mulai melakukan kegiatan untuk memasukkan larva BSF kedalam sampah. Sekitar $1 \mathrm{~kg}$ larva BSF dimasukkan ketempat sampah tersebut. Selanjutnya sampah yang telah di masukkan larva BSF diperhatikan dengan seksama oleh peserta. Larva BSF dengan rakus memakan sampah tersebut. Sekitar setengah hari sampah tersebut habis di makan oleh larva BSF. Hasil Kegiatan di sesi kedua ini sampah organik yang telah dikumpulkan dan membusuk di masukkan 1 kg larva BSF kedalam sampah organik sehingga larva tersebut mampu mereduksi sampah sekitar 2$3 \mathrm{~kg} \mathrm{sampah} / \mathrm{hari}$.

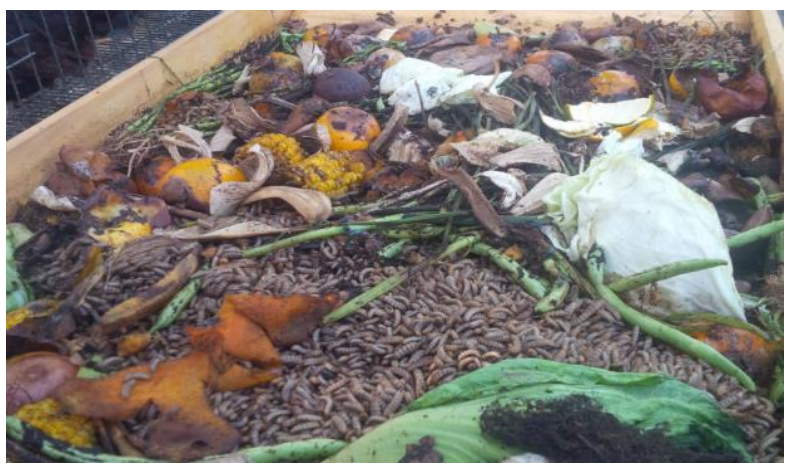

Gambar 4. Proses larva memakan sampah organik

Hasil pengabdian terdiri dari hasil secara kualitatif dari kegiatan yang dilaksanakan, yang mana dicapai bahwa larva BSF dapat membantu mengurangi sampah organik di Kelurahan Pardamean sehingga daerah tersebut bebas dari aroma yang tidak sedap akibat sampah organik yang lama membusuk. Kegiatan pelatihan ini ternyata memberikan pengetahuan yang baru bagi masyarakat terhadap pengolahan sampah organik. Selain dapat mengurangi jumlah sampah yang dihasilkan, juga memberikan nilai ekonomi peserta untuk membudidayakan larva BSF.

\section{SIMPULAN}

Peserta pelatihan menerima dan mempraktekkan teori yang disampaikan dengan baik. Tujuan utama kegiatan ini sudah tercapai dengan mengurangi sampah organik di masyarakat dengan menggunakan larva Black Soldier Fly (BSF). Dengan kegiatan ini peserta mampu mereduksi sampah organik sebanyak 2-3 kg/ perhari dengan larva $1 \mathrm{~kg}$.

\section{UCAPAN TERIMA KASIH}

Tim pengabdian mengucapkan terima kasih kepada Ibu Lurah di Kelurahan Pardamean Kota 
1114 Sosialisasi Penerapan Reduksi Sampah Organik Dari Larva Black Soldier Fly (FLY) - Febri Yanti DOI: https://doi.org/10.31004/abdidas.v2i5.434

Pematangsiantar dan Peserta Pelatihan Masyarkat

Kelurahan Pardamean Kota Pematangsiantar.

\section{DAFTAR PUSTAKA}

Ambarningrum, T. B., Srimurni, E., \& Basuki, E. (2019). Teknologi Biokonversi Sampah Organik Rumah Tangga Menggunakan Larva Lalat Tentara Hitam ( Black Soldier Fly / Bsf ), Hermetia Illucens ( Diptera: Stratiomyidae ). Prosiding Seminar Nasional Dan Call For Papers, 1, 235-243.

Azir, A., Harris, H., Bayu, R., \& Haris, K. (2017). Produksi Dan Kandungan Nutrisi Maggot (Chrysomya Megacephala) Menggunakan Komposisi Media Kultur Berbeda Production And Nutrition Maggot (Chrysomya Megacephala) Using Different Culture Media Composition. Jurnal Ilmu-Ilmu Perikanan Dan Budidaya Perairan, 12(1), 34-40.

Mudeng, N. E. G., Mokolensang, J. F., Kalesaran, O. J., Pangkey, H., \& Lantu, S. (2018). Budidaya Maggot (Hermetia Illuens) Dengan Menggunakan Beberapa Media. E-Journal Budidaya Perairan, 6(3), 1-6. Https://Doi.Org/10.35800/Bdp.6.3.2018.2154 3

Rini Fahmi, M., Hem, S., Wayan Subamia, Dan I., Riset Budidaya Ikan Hias Air Tawar Jl Perikanan No, L., \& Mas, P. (2009). Potensi Maggot Untuk Peningkatanpertumbuhan Dan Status Kesehatan Ikan. J. Ris. Akuakultur, 4(2), 221-232.

Salman, S., Ukhrawi, L. M., \& Azim, M. (2020). Budidaya Maggot Lalat Black Soldier Flies (BSF) Sebagai Pakan Ternak. Jurnal Gema Ngabdi, 2(1), 7-11. Https://Doi.Org/10.29303/Jgn.V2i1.40 